\title{
2 Mesenchymal stem cells secretome: a new paradigm for central nervous system regeneration?
}

\author{
Fábio G. Teixeira • Miguel M. Carvalho • \\ Nuno Sousa · António J. Salgado
}

Received: 16 November 2012 / Revised: 22 January 2013 / Accepted: 4 February 2013 (c) Springer Basel 2013

\begin{abstract}
The low regeneration potential of the central nervous system (CNS) represents a challenge for the development of new therapeutic strategies. Mesenchymal stem cells (MSCs) have been proposed as a possible therapeutic tool for CNS disorders. In addition to their differentiation potential, it is well accepted nowadays that their beneficial actions can also be mediated by their secretome. Indeed, it was already demonstrated, both in vitro and in vivo, that MSCs are able to secrete a broad range of neuroregulatory factors that promote an increase in neurogenesis, inhibition of apoptosis and glial scar formation, immunomodulation, angiogenesis, neuronal and glial cell survival, as well as relevant neuroprotective actions on different pathophysiological contexts. Considering their protective action in lesioned sites, MSCs' secretome might also improve the integration of local progenitor cells in neuroregeneration processes, opening a door for their future use as therapeutical strategies in human clinical trials. Thus, in this review we analyze the current understanding of MSCs secretome as a new paradigm for the treatment of CNS neurodegenerative diseases.
\end{abstract}

Keywords Mesenchymal stem cells - Secretome · Neurodegenerative diseases $\cdot$ Neuroregeneration

F. G. Teixeira and M. M. Carvalho contributed equally to this work.

F. G. Teixeira $\cdot$ M. M. Carvalho $\cdot$ N. Sousa $\cdot$ A. J. Salgado $($ 瓜 $)$ Life and Health Sciences Research Institute (ICVS), School of Health Sciences, University of Minho, 4710-057 Braga, Portugal e-mail: asalgado@ecsaude.uminho.pt

F. G. Teixeira · M. M. Carvalho $\cdot$ N. Sousa $\cdot$ A. J. Salgado PT Government Associated Lab, ICVS/3Bs, Braga/Guimarães, Portugal

\section{Introduction}

The use of stem cells as a new strategy for cell-based therapies has shown promising results in a variety of healthrelated problems, including neurodegenerative diseases [1]. In fact, during the last few years, there has been significant progress in the development of new protocols and strategies based on stem cells for the treatment of central nervous system (CNS) disorders [2, 3]. Indeed, studies have shown that they display some capability to differentiate into several cells types and also to exert trophic and protective actions [4-6]. Mesenchymal stem cells (MSCs) are a stem cell population that has emerged in the last few years as a promise in regenerative medicine of different tissues [7, 8]. This great potential has been associated with their widespread availability throughout the human body, along with the fact that, when isolated, they display great proliferative potential with minimal senescence through multiple passages $[9,10]$. According to the definition introduced by the International Society for Cellular Therapy (ISCT), there are some minimal criteria for the identification of MSCs populations, such as the adherence to plastic in standard culture conditions; positive expression of specific markers like CD73, CD90, CD105, and negative expression of hematopoietic markers like CD34, CD45, HLA-DR, CD14, or CD11B, CD79 $\alpha$ or CD19; and in vitro differentiation into at least osteoblasts, adipocytes, and chondroblasts [11]. Friedenstein and colleagues [12] were the first to isolate and describe MSCs in rodent bone marrow as fibroblastoid cells with clonogenic potential and plastic culture adherence. Following these early studies, several reports have confirmed that MSCs are not only present within the bone marrow but also in other tissues like adipose tissue $[13,14]$, dental pulp $[15,16]$, placenta [17, 18], umbilical cord blood [19], Wharton's jelly [20, 21], and brain [22]. Although all these populations

$\begin{array}{lll}\text { Journal : Large } \mathbf{1 8} & \text { Dispatch : 15-2-2013 } & \text { Pages : 12 } \\ \text { Article No : 1290 } & \square \text { LE } & \square \text { TYPESET } \\ \text { MS Code : 1290 } & \square \text { CP } & \text { 曰 DISK }\end{array}$


are within the definition of MSCs, they do present subtle differences, specifically in their membrane antigen markers. Studies have shown that such differences can be the result of different cell culture protocols in their isolation and expansion or, alternatively, be related with the tissue source from where they are isolated [23, 24]. Indeed, besides the membrane antigens proposed by ISCT for the characterization of MSCs-CD73, CD90, and CD105-other membrane antigens including CD29, CD44, CD51, CD71, CD106, and Stro-1 have also been associated with a MSCs identity $[23,25,26]$. In addition to these findings, further studies demonstrated that all these MSCs populations could be sub-passaged and differentiated in vitro into different cell lineages such as osteoblasts, chondrocytes, adipocytes, and myoblasts [26, 27]. Curiously, several reports also showed that MSCs could also differentiate into neuronal and epithelial populations [26, 28-31]. While the differentiation into epithelial cells seems to occur, the differentiation of MSCs into functional neuronal lineages is still matter of intense debate [26, 32].

In this sense, in addition to the need of clarifying the phenotypic identity of MSCs and the best culture parameters for their handling, it also becomes important to characterize MSCs' secretome in order to understand if in fact the factors secreted by these cells may be the main effectors of their therapeutic actions. For that, on the scope of this review, we will discuss the current understanding of MSCs' secretome in particular the ones isolated from bone marrow (BM-MSCs), adipose tissue (ASCs) and Wharton Jelly of the umbilical cord (WJSCs/HUCPVCs). Moreover, we will also review recent experimental data addressing the therapeutical potential of all these different MSC populations in CNS lesion models specifically in spinal cord injury (SCI), ischemic stroke (IS), and Parkinson's disease (PD).

\section{Secretome}

In recent years, it is becoming increasingly accepted that the regenerative effects promoted by MSCs are mainly associated with the secretion of bioactive molecules, that is, with their secretome [33]. The concept of the secretome has been defined as the proteins which are released by a cell, tissue, or organism being afterwards crucial on the regulation of different cell processes [34]. Therefore, today it is believed and accepted that in response to injury, MSCs have the capacity to migrate to the damage site and promote the repair process through the secretion of growth factors, cytokines, as well as antioxidants [35, 36]. Moreover, according to Wagner and colleagues [37], the secretion of all these factors may be dependent on the type and stage of injury. Nevertheless, despite this notion of growth factors and cytokines being associated with the cellular secretome, nowadays, it has been also suggested that MSCs seem to be able to secrete large amounts of micro or nano-vesicles such as exosomes [38]. Although its potential has not been clarified so far, some authors have attributed important features to this kind of structures such as the transference of proteins and genetic material (e.g., RNA) to other cells [39-42]. For these reasons, several authors believe that beyond cellcell interaction, the secretome of MSCs could be the main reason of their immunomodulation and regenerative capacity in the lesion site [43, 44]. Although studies suggest that MSCs transcriptome/secretome can be modulated with different environment conditions, it also becomes important to analyze how far these changes can be relevant according to the normal or pathological conditions in which they are being applied $[32,45]$. Therefore, it has been suggested that these protective actions promoted by MSCs secreted molecules may explain their remarkable therapeutic plasticity in the CNS $[9,46]$. As a consequence of this, Caplan and Dennis [47] have recently classified MSCs as important trophic mediators. Concerning BM-MSCs, these authors considered that in addition to their potential to differentiate into different cell lineages, these cells are also able to secrete a panel of growth factors and cytokines with direct effects into a variety of mechanisms such as immune system suppression, inhibition of apoptosis, increase of angiogenesis, and stimulation of tissue adjacent cells [47].

Crigler and coworkers [48] were the first to demonstrate that BM-MSCs were able to promote neuronal survival and neuritogenesis through the secretion of neurotrophic factors such as BDNF and beta-NGF in vitro. Recently, from a characterization study of the conditioned media (CM) of BM-MSCs, Nakano and coworkers [49] demonstrated that these cells were able to secrete IGF-1, HGF, VEGF, and TGF- $\beta$, which were related with higher levels of neuronal survival and neurite outgrowth in vitro. In line with this, further studies also showed that the CM of BM-MSCs was also able to promote neuronal and glial survival in vitro $[50,51]$. In addition to these findings, when applied into animal models of Parkinson's disease and spinal cord injury, BMMSCs were also able to release a panel of different trophic factors, such as BDNF, FGF-2, GDNF, and IGF-1, a fact that could explain not only the increase of neuronal survival after lesion but also the improvement of animal behavior upon cell transplantation $[52,53]$.

Similar to what has been reported for BM-MSCs growth factors such VEGF, HGF, bFGF, IGF1, TGF- $\beta 1$, and others have also been found in the ASCs secretome [54, 55]. In vitro, Lu and coworkers [56] revealed that ASCs secretome was able to exert an active protection in a PC12 cell line model against the induction of glutamate excitotoxicity. This result was partially correlated with the presence of different levels of VEGF, HGF, and BDNF [56]. Similarly, another study using the same cell line revealed that ASCs-CM was

\begin{tabular}{lll|} 
Journal : Large 18 & Dispatch : 15-2-2013 & Pages : 12 \\
Article No : $\mathbf{1 2 9 0}$ & $\square$ LE & $\square$ TYPESET \\
MS Code : $\mathbf{1 2 9 0}$ & $\square$ CP & $\square$ DISK
\end{tabular}


able to induce neuritogenesis, relating this effect with the presence of secreted NGF [57]. Wei and coworkers [58] demonstrated that after incubation of cerebellar granule neurons with ASCs-CM, a significant increase in protection against apoptosis was observed through the action of IGF-1 present in ASCs-CM. Recently, our group has also revealed, in vitro, that ASCs-CM was able to increase the viability of neuronal and glial populations through the presence of NGF, SCF, HGF, and VEGF in their secretory profile [59]. In vivo, several reports have already demonstrated a trophic benefit promoted by ASCs $[60,61]$. For instance, Lopatina et al. [62] showed that ASCs were able to stimulate the regeneration of peripheral nerves through the secretion of BDNF, promoting de novo axon growth. Finally, concerning WJ-MSCs and HUCPVCs, studies already showed that they are also able to contain neurotrophic factors in their secretome [59, 63, 64]. Recently, Salgado and coworkers [64] verified that the CM of IIUCPVCs was able to increase the proliferation and the survival of primary cultures of hippocampal neurons and glial populations. In line with this, Ribeiro et al. [59] also showed similar results, demonstrating that HUCPVCs CM was able to secrete NGF and VEGF. Koh and coworkers [63], performing an objective analysis of WJ-MSCs secretome, revealed that the secretion of G-CSF, VEGF, GDNF, and BDNF could be correlated with their neuroprotective effect when transplanted in vivo. Similar observations were also found by Ding and colleagues [65], which revealed that after transplantation in a model of stroke, WJ-MSCs were able to promote functional recovery, reduction of lesion size, as well as to express high levels of SDF-1, BDNF, and GDNF. Recently, our group further demonstrated that the secretome of HUCPVCs was able to increase the secretion levels of neurotrophic factors such as BDNF, NFG, and FGF-2 in the dentate gyrus of the hippocampus, contributing for the increase of neural proliferation, survival, and differentiation. Altogether, these facts, strongly suggest that the soluble factors secreted by MSCs populations may explain their apparently therapeutic effect both in vitro and in vivo. Nonetheless, a deep analysis of the factors existing in their secretome in the context of different pathophysiological conditions is still lacking. In fact, despite the inexistence of a full characterization of MSCs secretome, studies have already shown that the use of MSCs as well as their trophic action could be a potential therapeutic tool in the regenerative processes of some neurodegenerative disorders such as Parkinson's disease, stroke, and spinal cord injury $[52,66,67]$.

\section{Parkinson's disease}

Parkinson's disease (PD) is a neurodegenerative disorder that is characterized by the progressive degeneration of dopaminergic neurons (DA) in several dopaminergic networks, most intensively in the mesostriatal pathway at the level of the substantia nigra pars compacta $(\mathrm{SNc})[68,69]$ (Fig. 1). As a result, patients develop several motor complications including rigidity, bradykinesia, and postural instability [70]. The application of Levodopa (L-dopa) or DA agonists has been considered the gold standard

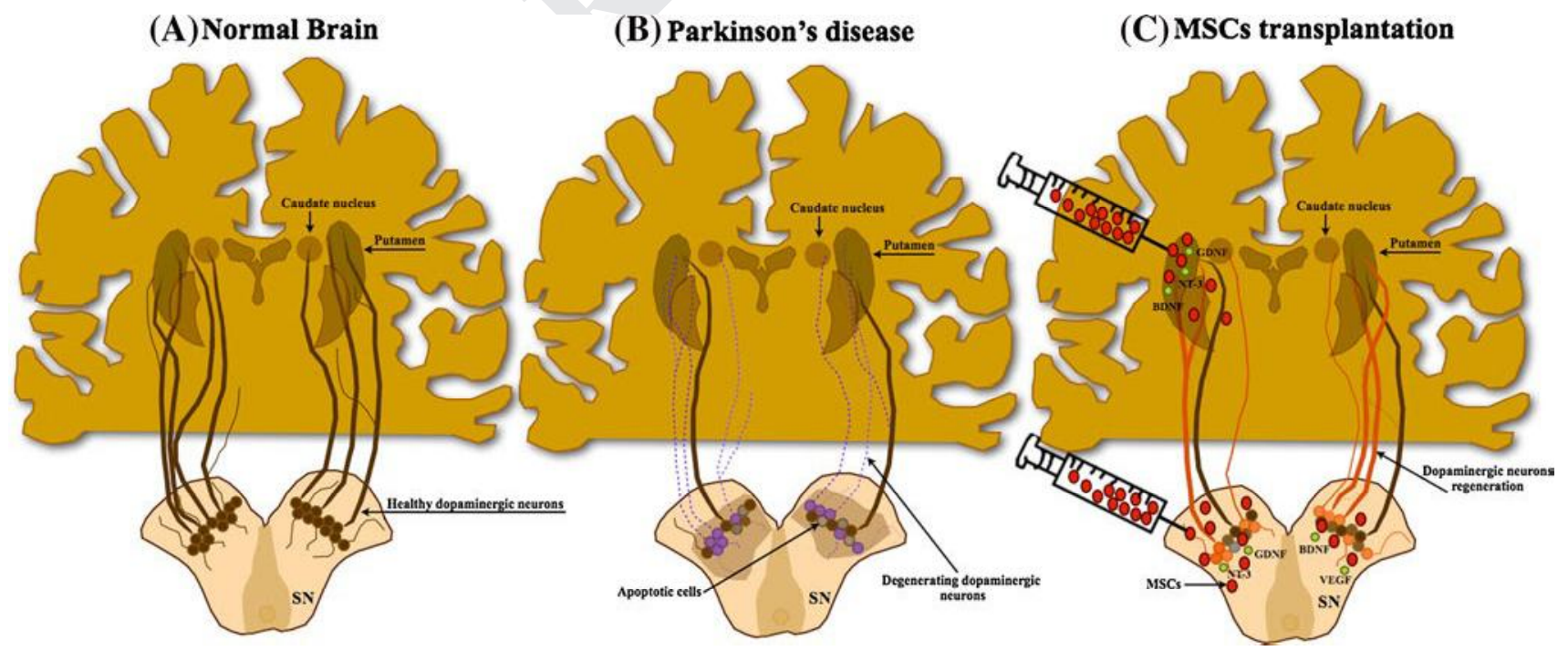

Fig. 1 Mesenchymal stem cell-based therapy for PD. PD is characterized by a progressive neuronal death of dopaminergic neurons in multiple dopaminergic networks, most intensively in the nigrostriatal pathway leading to motor complications $(\mathbf{a}, \mathbf{b})$. The transplantation of MSCs has emerged as possible therapeutic tool due to their prolifera- tion and differentiation capacity (c). The ability to release growth and trophic factors seems to be one of the reasons for their contribution to the protection/survival of the preexisting dopaminergic neurons in lesioned areas, leading to functional amelioration and improvement of motor function. ( $S N$ substantia nigra)

\begin{tabular}{lll|} 
Journal : Large 18 & Dispatch : 15-2-2013 & Pages : 12 \\
Article No : $\mathbf{1 2 9 0}$ & $\square$ LE & $\square$ TYPESET \\
MS Code : $\mathbf{1 2 9 0}$ & $\square \mathrm{CP}$ & $\square$ DISK \\
\hline
\end{tabular}


treatment for PD as well as for the easement of its major symptoms [71]. However, despite its improving action on behavior performance, most of these treatments have shown some limitations such as undesirable side effects, non-total recovery of PD symptomatology, long-term inefficiency, as well as an inability to recover lost DA neurons or to protect the remaining ones [72-74]. Due to these limitations, and based on the rationale that cell transplantation approaches could be beneficial in restoring degenerated $\mathrm{DA}$ pathways and ameliorate the behavioral outcome, some clinical trials were conducted in the 1990s [75-78]. These were based on the transplantation of human fetal mesencephalic tissue and the results were quite promising, with patients displaying an increased DA synthesis, improved motor function, and reduction of required doses of L-dopa [71]. These studies confirmed the relevance and feasibility of cell-based transplantation techniques to treat $\mathrm{PD}$, but because of methodological and ethical related with manipulation of human fetal tissue other cell sources needed to be found [79]. MSCs cell-based applications have thus emerged as a potential therapy for PD [80-82] (Fig. 1). Although the literature continues to look carefully on its application as a tool for the treatment of PD in humans, several studies in PD animal models have shown that transplantation of BMMSCs, ASCs, or WJ-MSCs, seem to contribute to neuroprotection and/or neural recovery [83-85]. Indeed, it was already demonstrated that after transplantation, these cells were able to increase the levels of tyrosine hydroxylase (TH) and dopamine levels when compared with untransplanted animals [86, 87]. For instance, with ASCs, McCoy and colleagues [84] demonstrated that after autologous transplantation, these cells were able to attenuate 6-OHDA-induced nigrostriatal pathway degeneration and behavioral deficits even without dopaminergic differentiation. Despite this, Thomas and colleagues [88] reported that, ideally, MSCs should only be considered an alternative and credible source of replacement DA cells when their ability to transdifferentiate into neuronal lineages is clarified both morphologically and functionally. Thus, while some studies propose the differentiation capacity of MSCs into DA neurons or neural lineages as the principal effector of PD recovery, it has also been suggested that this functional improvement can be caused by the release of trophic factors in vivo [33, 52]. For instance, Cova and colleagues [52], using a 6-OHDA model of PD, demonstrated that BMSCs have the capacity to interact with the surroundings of the lesion site, which indicates their ability to maintain their phenotype even under nonphysiological conditions. In addition to this finding, these authors also observed an active secretion of trophic factors like EGF, VEGF, NT3, FGF-2, HGF, and BDNF for a long period of time in vivo, demonstrating that BM-MSCs did not require the acquisition of neuronal phenotype to exert a neuroprotective action in dopaminergic populations [52].
Moreover, Wang et al. [89] demonstrated that BM-MSCs could exert neuroprotection against 6-OHDA-exposed dopaminergic neurons both in vitro and in vivo through antiapoptotic mechanisms promoted by the expression of SDF-1. Likewise, using the same model, Weiss and colleagues demonstrated that WJ-MSCs are also able to secrete trophic factors in vivo [90]. Contrary to the observed in the previous study, these authors associate the recovery of TH-positive cells and behavioral amelioration to the significant secretion of GDNF and FGF-20 [90]. In line with this, the protection and survival of dopaminergic neurons through the secretion of GDNF, BDNF, and NGF was also achieved with ASCs [84]. Moreover, other studies even proposed intrastriatal transplantation of hMSCs as a good method for the functional rescue of nigrostriatal dopaminergic networks and improvement of behavioral impairments in PD models, mainly due to their secretion capacity in vivo [91, 92]. For this reason, it is strongly suggested that hMSCs may in fact represent a valid tool for the neuroprotection and survival of the dopaminergic neurons through the release of a panel of multiple trophic factors [93]. Nowadays, studies have suggested the genetic modification of hMSCs as a new strategy to secrete specific trophic factors such as GDNF into the striatum and SNc, having in view the long-term amelioration of PD pathophysiology [94, 95].

\section{Spinal cord injury (SCI)}

SCI is characterized by long-term functional deficits in ascending and descending motor and sensitive neuronal pathways as a result of accidental injury, in most of the cases leading to a complex cascade of reactions that result in loss of neurons and glial cells, inflammation, demyelination, and pain [96, 97] (Fig. 2). The occurrence of this kind of lesion creates a non-permissive inflammatory and chemical environment along with abnormal secretion and accumulation of neurotransmitters, generating high excitotoxicity levels with destructive actions for neuronal function and regeneration $[67,96]$. The application of pharmacological treatments has been, according with the literature, the best approach for SCI neuroprotection [98]. However, despite the multiple treatments that were developed and those that are being developed and applied, most of these trials have failed to show significant efficacy in the recovery of sensory-motor function, leaving many patients facing significant neurologic dysfunction and disability [98].

Cell-based therapies through the use of MSCs have grown in the last few years as a potential promise for SCI applications $[60,99]$. Despite the complexity of SCI lesions, transplantation with BM-MSCs has already shown that these cells were able to promote remyelination, axonal sparing, and functional recovery in different SCI stages [100,

\begin{tabular}{lll|} 
Journal : Large 18 & Dispatch : 15-2-2013 & Pages : 12 \\
Article No : 1290 & $\square$ LE & $\square$ TYPESET \\
MS Code : $\mathbf{1 2 9 0}$ & $\square \quad C P$ & $\square$ DISK \\
\hline
\end{tabular}


(A) Normal Spinal Cord

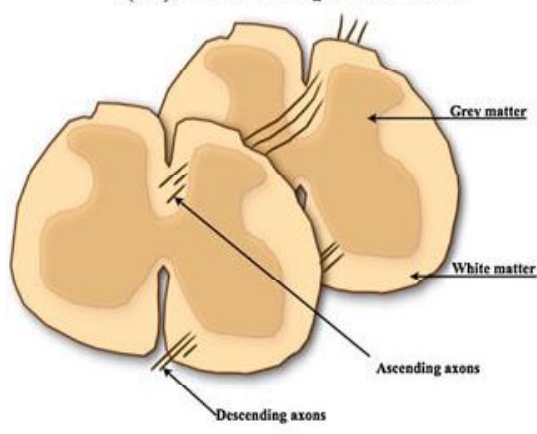

(B) Spinal Cord Injury

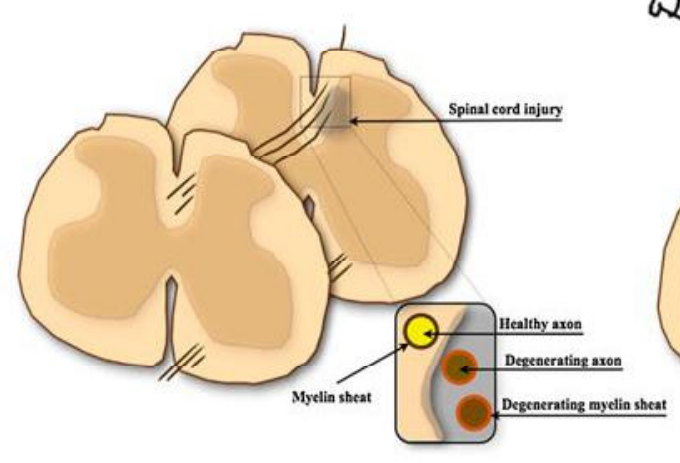

(C) MSCs Transplantation

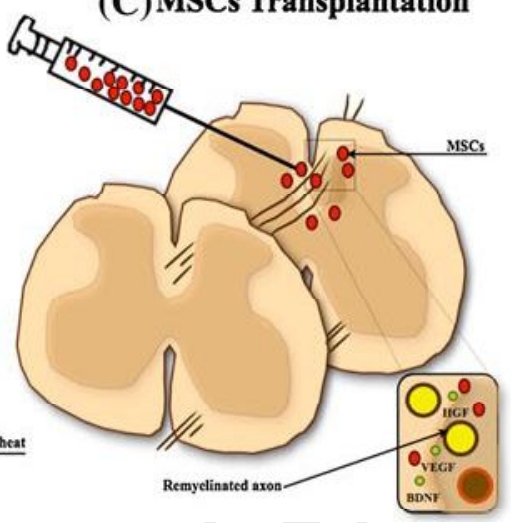

Fig. 2 Mesenchymal stem cell-based therapy for SCI. SCI leads to immediate neuronal and glial cell death with interruption of ascending and descending pathways, followed by intense inflammatory reaction and glial scar formation (a, b). The transplantation of MSCs has been described to contribute for the recruitment of new neural stem cells, neuronal and glial cells, promoted by cell-cell interaction or

101]. Moreover, it has been hypothesized that MSCs have the capacity to migrate to the lesion site, survive for a long period of time and improve animal behavior [102, 103] (Fig. 2). Although studies suggest that MSCs promote functional recovery after transplantation in SCI, the precise mechanism of action remains still unclear [104]. Besides the fact that MSCs are immunosuppressive, studies have shown that they can modify the SCI milieu directly through the release of trophic factors such as BDNF, NGF, and VEGF, promoting axonal regeneration, neurite outgrowth, and glial scar reduction [48, 105] (Fig. 2). Lu and coworkers [106] showed that after transplantation of BM-MSCs, they were able to secrete NGF, NT-3, and high levels of BDNF, contributing to the extent of host axonal growth, and enhancing the growth of host serotonergic, coerulospinal, and dorsal column sensory axons after SCI. Similar findings were also reported by Neuhuber et al. [107], which demonstrated that the CM of BM-MSCs was able to promote axon growth and functional recovery due to the presence of BDNF, VEGF, IL-6, MCP-1, SCF, and SDF-1 $\alpha$ in its composition. Recently, Gu et al. and Park et al. $[108,109]$ showed that these cells were able to secrete neurotrophic factors such as HGF, VEGF, BDNF, and GDNF, suggesting that this secretory activity could be the main reason to promote axonal regeneration of spinal neurons both in vitro and in vivo. Concerning ASCs, it was also shown that these could be similar to Schwann cells, secreting neurotrophic factors such as BDNF and improving re-myelination [62]. Moreover, predifferentiated ASCs can be yet another promising approach for axonal regeneration that has been associated with their paracrine action [60]. With WJSCs, so far only two studies have examined their use in SCI. Nonetheless, the outcome of these studies indicates that WJSCs by the release of cytokines, and trophic factors (c). The secretion of these cytokines and trophic factors seems to be the main effector of neuroprotective processes and for reduction of the glial scar, modulation of inflammation, and stimulation of the remyelination (adapted from Lindvall and Kokaia [2])

transplantation into SCI was able to potentiate repair and recovery due to the release of trophic factors such as NT-3, VEGF, bFGF, and BDNF $[102,110]$.

Clinical approaches using the transplantation of MSCs, namely BM-MSCs, indicate that they may have an application for clinical SCI [111-113]. In a pilot study, Saito and colleagues [114] demonstrated that the autologous transplantation of BM-MSCs by lumbar puncture seems to be safe and relevant for the patients, leading to motor improvement. Similar results were also obtained by Karamouzian and colleagues [112] in subacute SCI stages. In this study, after the transplantation of the BM-MSCs, the authors observed that $45.5 \%$ of the patients presented improvements in their neurological and motor function [112]. However, the precise mechanism that could explain this recovery after transplantation is still unclear. As discussed in the animal model experiments, some authors considered that the transdifferentiation of MSCs into neural lineages or their secretome through the release of growth and trophic factors seems to be the main reason for the improvement of the condition of the patients $[111,115]$. Although the application of these cells is still highly experimental, evidence suggests that MSCs-based therapies could in fact be a new approach for the regeneration of SCI tissue damage, providing neuroprotection and trophic support for the prevention of cell death and axonal degeneration $[116,117]$.

\section{Ischemic stroke (IS)}

Cerebrovascular diseases, such as stroke, represent a kind of lesion that results from blood vessel occlusion or damage, leading to focal tissue loss and death of endothelial cells

$\begin{array}{lll}\text { Journal : Large } \mathbf{1 8} & \text { Dispatch : 15-2-2013 } & \text { Pages : 12 } \\ \text { Article No : 1290 } & \square \text { LE } & \square \text { TYPESET } \\ \text { MS Code : 1290 } & \square \text { CP } & \square \text { DISK }\end{array}$


(A) Normal Brain

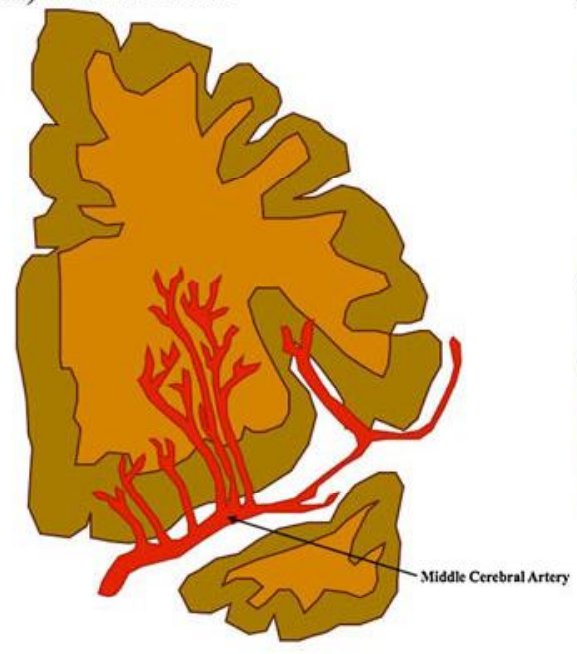

(B) Stroke

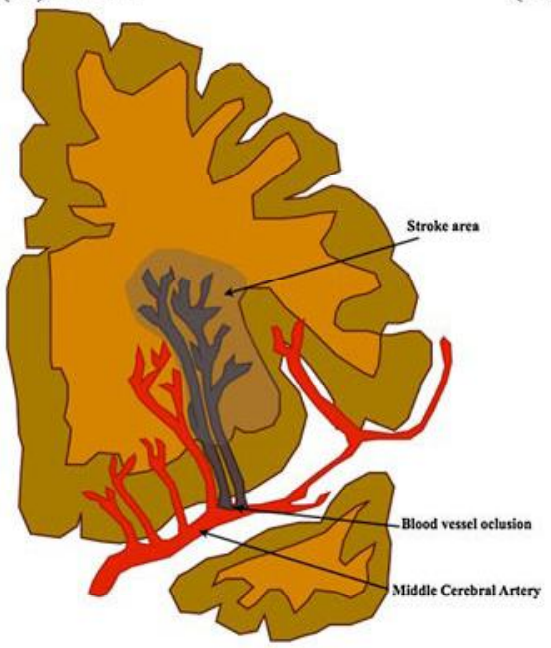

(C)MSCs transplantation

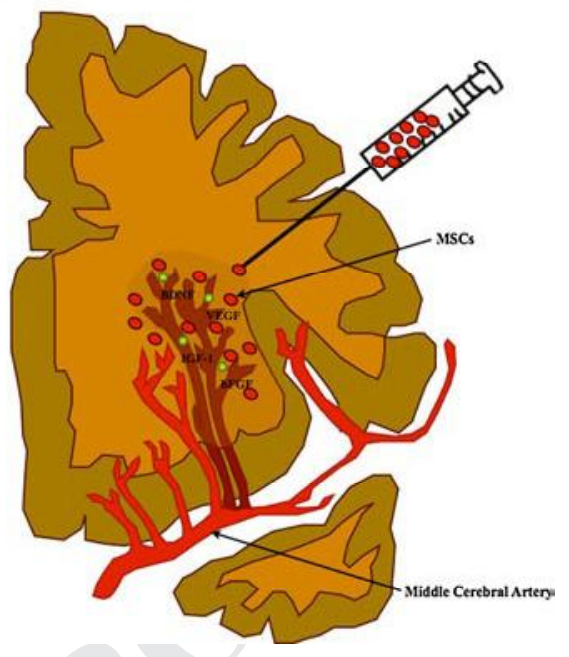

Fig. 3 Mesenchymal stem cell-based therapy for stroke. This pathology is caused by occlusion of a cerebral artery, leading to focal tissue loss with death of different neural cells, including neurons and glial cells as well as endothelial cells $(\mathbf{a}, \mathbf{b})$. MSCs transplantation has been shown to have a beneficial role in the reduction of lesion size and multiple neural populations [2, 118] (Fig. 3). Additionally, other events are associated with it, including acidosis caused by anaerobic glucose metabolism, intracellular calcium accumulation and excitotoxicity, which leads to high levels of glutamate release, and excessive production of free radicals and inflammatory mediators $[119,120]$. It has been proposed that the transplantation of MSCs could also be a feasible therapeutic option for IS [66, 121]. Indeed, studies have shown that after intravenous administration of BM-MSCs, these have the capacity to migrate to lesion site promoting tissue regeneration and behavioral improvement [122]. Moreover, studies have suggested that these cells were not only able to promote the recovery of animal behavior but also to increase the levels of neurogenesis, providing the survival of neuroblasts and to reduce the volume of lesion after IS $[123,124]$. In addition to this finding, previous studies also showed that the possible mechanism that could be associated with this phenomenon resides in their capacity to migrate selectively to ischemic lesion through the action of SDF-1, and in their trophic and differentiation capacity into neural/glial cells $[125$, 126]. Indeed, it has been reported in animal models that MSCs are indeed involved in the production and increase in the levels of trophic factors such as IGF-1, VEGF, EGF, BNDF, and bFGF which, according to Wakabayashi and colleagues [127], seem to be the responsible mechanisms in the reduction of lesion size and in the modulation of inflammatory environment for host cells. In a recent report, Leu and colleagues [128] proposed that much like BM-MSCs, ASCs therapy also enhances angiogenic and neurogenic and in the protection of surviving cells (c). The secretion of growth and trophic factors has been associated with motor and functional recovery, having a key role on neuroprotection and modulation of inflammation

processes. Additionally, these authors also saw that ASCs application was able to increase the number of small vessels in the lesion site, and a possible reason explaining recovery of neurological function observed. Although the exact mechanism of these cells still remains unclear, other studies have suggested that homing properties, cytokines (SDF-1 $\alpha$, IL-1, IL-8) effects, and paracrine mediators (HGF, BDNF, IGF-1, VEGF) could pinpoint ASCs effects, contributing to tissue regeneration and functional behavior [129-131]. This way, the secretion of growth factors and cytokines by ASCs could be a potential tool not only to promote repair through the induction of progenitor cells to differentiate and replace lost tissues but also to activate of survival and anti-inflammatory pathways [58]. Wei and colleagues [58] were the first to show that application of ASC-CM in brain damage was able to exert neuroprotection blocking the neuronal damage and tissue loss through the factors present in their composition particularly IGF-1 and BDNF. Regarding WJ-MSCs, Ding and coworkers [65] demonstrated that they can also be beneficial for the treatment of brain ischemia. A high expression of SDF-1, BDNF, and GDNF was found after WJ-MSCs implantation, suggesting that these cells have the ability to activate molecular pathways involved in neuroprotection processes. In line with this, Koh and colleagues [63] also demonstrated that WJ-MSCs can indeed be seen as a therapeutical alternative to use in stroke, given that they proved this cells to be able to secrete more trophic factors than BM-MSCs after transplantation, namely G-CSF, VEGF, GDNF, and BDNF. However, despite the fact that WJ-MSCs do not differentiate into functional

\begin{tabular}{lll|} 
Journal : Large 18 & Dispatch : 15-2-2013 & Pages : 12 \\
Article No : 1290 & $\square$ LE & $\square$ TYPESET \\
MS Code : $\mathbf{1 2 9 0}$ & $\square \quad C P$ & $\square$ DISK \\
\hline
\end{tabular}


neurons and remain undifferentiated after transplantation, it was shown that they exhibit an exciting migratory tropism to the lesion site which, combined with the production of trophic factors, might foster the creation of new networks between the host neural and transplanted stem cells [63]. Concerning the clinical application of MSCs, few studies have been performed. For instance, in 2005, Bang and colleagues [132] demonstrated that transplantation of BM-MSCs had no adverse cell response and improved the neurological function of patients. Recently, Lee and colleagues [133] also showed that after long-term application of the same cell population, there was a safe improvement in the neurological and in the motor function of the patients. As in the case of SCI patients, the precise mechanism that could explain the recovery of stroke patients remains still unclear; however, evidences have associated the clinical improvement with the increase of serum levels of SDF-1 $\alpha$ as well as with the increase of neurogenesis in the subventricular zone of the lateral ventricle [133]. Although some studies suggest that the secretion of neurotrophic factors could be the most likely reason for the improvement of stroke impairments, more studies are needed in order to clarify the precise action and interaction of MSCs and their factors with the resident cells where they are being implemented $[134,135]$.

\section{Conclusions and perspectives}

Neurodegenerative diseases are indeed chronic and acute insults against the homeostasis of the CNS, capable of promoting a large amount of cell death in neural populations in the brain and spinal cord. Thus, as a result of the limited capacity of the CNS to self-repair, the design of new therapeutical strategies represents a major challenge for CNS regenerative approaches. Due to their capacity of self-renew and multilineage differentiation potential, MSCs have been suggested as possible therapeutic tools for regenerative medicine, representing a promising cell source for the creation of new cell-based therapies [7, 79, 136, 137]. When compared to other sources they do not imply the ethical and moral issues raised by embryonic stem cells (ESCs) or the technical issues regarding the isolation and further in vitro expansion of neural stem cells (NSCs). Throughout the years it has become evident that MSCs might have a role in future stem cell-based therapeutic strategies for CNS regeneration [138]. Initially, these effects were attributed to a possible neural differentiation of MSC-like cells (Fig. 4) [139]; however, this apparently ability of neuronal differentiation, both in vitro and in vivo conditions, remains still under discussion (e.g., some authors have suggested that cell fusion

\section{5}

Fig. 4 Mechanisms of action of MSCs in the CNS. a The transdifferentiation capacity of MSCs into neuronal and glial lineages both in vitro and in vivo was described over the years as the probable explanation by their beneficial outcomes after transplantation in the CNS, although this concept remains still unclear. b The trophic action of MSCs has been increasingly accepted nowadays as a new concept to the regeneration of the CNS. The secretion of growth and neurotrophic factors by these cells has been described as an assistant in the nervous tissue regeneration through the activation/modulation of some endogenous processes like the promotion of neurogenesis, angiogenesis, and immunomodulation, contributing in this way to the neuroprotection and regeneration of the CNS

\begin{tabular}{lll|} 
Journal : Large 18 & Dispatch : 15-2-2013 & Pages : 12 \\
Article No : $\mathbf{1 2 9 0}$ & $\square$ LE & $\square$ TYPESET \\
MS Code : $\mathbf{1 2 9 0}$ & $\square$ CP & $\square$ DISK
\end{tabular}


Table 1 Examples of clinical approaches using mesenchymal stem cells for stroke and SCI repair/regeneration

\begin{tabular}{|c|c|c|}
\hline Kind of injury & Outcomes & Reference \\
\hline \multirow[t]{2}{*}{ Stroke } & $\begin{array}{l}\text { No adverse cell response; reduction of infarct size; neurological } \\
\text { function improvement }\end{array}$ & [132] \\
\hline & $\begin{array}{l}\text { Safe application of MSCs after long period; no zoonoses after } \\
\text { treatment; increase of functionality and survival; clinical } \\
\text { improvement correlated with the increase of SDF- } 1 \alpha \text { plasma levels }\end{array}$ & [133] \\
\hline \multirow[t]{3}{*}{ Spinal cord injury } & $\begin{array}{l}\text { No adverse reaction to the transplantation in the CSF; the release } \\
\text { of some trophic factors was associated with neuronal/glial } \\
\text { neuroprotection }\end{array}$ & [113] \\
\hline & $\begin{array}{l}\text { Patients followed up for 1-4 years did not present any kind of } \\
\text { adverse response; BM-MSCs were highly effective, promoting } \\
\text { a remarkable recovery in the patients; intrathecal administration } \\
\text { of MSCs is a safe method }\end{array}$ & [114] \\
\hline & $\begin{array}{l}\text { No adverse reaction to the transplantation such as fever or headache; } \\
\text { most of the patients showed amelioration in their neurological } \\
\text { function after transplantation }\end{array}$ & [112] \\
\hline
\end{tabular}

is a phenomenon to be considered that could lead to a false immunopositive characterization of MSCs as neural cells) $[32,140]$. Nowadays, there is ample evidence strongly suggesting that most of the effects promoted by MSCs might reside in their secretome (Fig. 4) [51, 58, 64, 141]. Indeed, it has already been shown, both in vitro and in vivo, that MSCs secrete a variety of neurotrophic factors such as IGF-1, BDNF, VEGF, GM-CSF, FGF2, and TGF-B, having a prominent role in the inhibition of scarring, apoptosis, immune response modulation, neurogenesis, and angiogenesis $[9,47,79,137]$. Concerning the clinical application of MSCs, few studies were done so far and only in stroke and SCI (Table 1). However, there are still many variables regarding its application as a new therapy for neurological disorders, which need to be further addressed. Despite the promising results already described, the source of MSCs, culture conditions, transplantation parameters (e.g., cell numbers and site), timing of treatment, as well as the route of delivery represent some of the issues that need to be clarified in order to create a safe therapy [142]. Although the neural differentiation of MSCs is still considered a possible explanation to some authors, their secretome seems to be nowadays the main reason of their therapeutic effect after transplantation $[32,52,115,133]$. Studies have shown that the molecules secreted by MSCs seem to assist the nervous tissue regeneration through the activation/modulation of endogenous neuro-restorative processes [115, 143-145]. In this sense, a thorough characterization of these MSCs' secretome becomes necessary not only to identify the full scope of factors released but also to clarify if in fact the molecules released are able to modulate not only the immune response but also different cell processes such as cell proliferation, differentiation, and survival in different physiological conditions $[92,146,147]$. At the same time, new protocols must be developed in order to examine the MSCs secretome in vivo, as well as strategies to modulate it [141].
By doing this, it will be possible to understand if in fact the secretome of these cells may be used as a new therapeutic strategy in CNS regenerative medicine.

Acknowledgments We thank the Portuguese Foundation for Science and Technology (FCT) for Ciência 2007 program (A.J. Salgado) and pre-doctoral fellowships to F.G. Teixeira (SFRH/BD/69637/2010) and Miguel Carvalho (SFRH/BD/51061/2010).

\section{References}

1. Gogel S, Gubernator M, Minger SL (2011) Progress and prospects: stem cells and neurological diseases. Gene Ther 18(1): $1-6$

2. Lindvall O, Kokaia Z (2010) Stem cells in human neurodegenerative disorders-time for clinical translation? J Clin Invest 120(1):29-40

3. Lindvall O, Barker RA, Brustle O et al (2012) Clinical translation of stem cells in neurodegenerative disorders. Cell Stem Cell 10(2):151-155

4. Becerra J, Santos-Ruiz L, Andrades JA et al (2011) The stem cell niche should be a key issue for cell therapy in regenerative medicine. Stem Cell Rev 7(2):248-255

5. Chen FM, Wu LA, Zhang M et al (2011) Homing of endogenous stem/progenitor cells for in situ tissue regeneration: promises, strategies, and translational perspectives. Biomaterials 32(12): 3189-3209

6. Chen FM, Zhao YM, Jin Y et al (2012) Prospects for translational regenerative medicine. Biotechnol Adv 30(3):658-672

7. Kassem M, Kristiansen M, Abdallah BM (2004) Mesenchymal stem cells: cell biology and potential use in therapy. Basic Clin Pharmacol Toxicol 95(5):209-214

8. Wang S, Qu X, Zhao RC (2011) Mesenchymal stem cells hold promise for regenerative medicine. Front Med 5(4):372-378

9. Uccelli A, Benvenuto F, Laroni A et al (2011) Neuroprotective features of mesenchymal stem cells. Best Pract Res Clin Haematol 24(1):59-64

10. Uccelli A, Laroni A, Freedman MS (2011) Mesenchymal stem cells for the treatment of multiple sclerosis and other neurological diseases. Lancet Neurol 10(7):649-656

11. Dominici M, Le Blanc K, Mueller I et al (2006) Minimal criteria for defining multipotent mesenchymal stromal cells. The

\begin{tabular}{lll|} 
Journal : Large 18 & Dispatch : 15-2-2013 & Pages : 12 \\
Article No : 1290 & $\square$ LE & $\square$ TYPESET \\
MS Code : $\mathbf{1 2 9 0}$ & $\square \quad C P$ & $\square$ DISK \\
\hline
\end{tabular}


International Society for Cellular Therapy position statement. Cytotherapy 8(4):315-317

12. Friedenstein AJ, Deriglasova UF, Kulagina NN et al (1974) Precursors for fibroblasts in different populations of hematopoietic cells as detected by the in vitro colony assay method. Exp Hematol 2(2):83-92

13. Zuk PA, Zuk M, Ashjian P et al (2002) Human adipose tissue is a source of multipotent stem cells. Mol Biol Cell 13(12):4279-4295

14. Zuk PA, Zuk M, Mizuno H et al (2001) Multilineage cells from human adipose tissue: implications for cell-based therapies. Tissue Eng 7(2):211-228

15. Gronthos S, Mankani M, Brahim J et al (2000) Postnatal human dental pulp stem cells (DPSCs) in vitro and in vivo. Proc Natl Acad Sci USA 97(25):13625-13630

16. Shi S, Gronthos S (2003) Perivascular niche of postnatal mesenchymal stem cells in human bone marrow and dental pulp. J Bone Miner Res 18(4):696-704

17. Fukuchi Y, Nakajima H, Sugiyama D et al (2004) Human placenta-derived cells have mesenchymal stem/progenitor cell potential. Stem Cells 22(5):649-658

18. Abumaree MH, Al Jumah M, Kalionis B et al. (2012) Phenotypic and functional characterization of mesenchymal stem cells from chorionic villi of human term placenta. Stem Cell Rev

19. Erices A, Conget P, Minguell JJ (2000) Mesenchymal progenitor cells in human umbilical cord blood. Br J Haematol 109(1):235-242

20. Wang HS, Hung SC, Peng ST et al (2004) Mesenchymal stem cells in the Wharton's jelly of the human umbilical cord. Stem Cells 22(7):1330-1337

21. Weiss ML, Troyer DL (2006) Stem cells in the umbilical cord. Stem Cell Rev 2(2):155-162

22. Paul G, Ozen I, Christophersen NS et al (2012) The adult human brain harbors multipotent perivascular mesenchymal stem cells. PLoS One 7(4):e35577

23. Chamberlain G, Fox J, Ashton B et al (2007) Concise review: mesenchymal stem cells: their phenotype, differentiation capacity, immunological features, and potential for homing. Stem Cells 25(11):2739-2749

24. Meirelles Lda S, Fontes AM, Covas DT et al (2009) Mechanisms involved in the therapeutic properties of mesenchymal stem cells. Cytokine Growth Factor Rev 20(5-6):419-427

25. Phinney DG (2007) Biochemical heterogeneity of mesenchymal stem cell populations: clues to their therapeutic efficacy. Cell Cycle 6(23):2884-2889

26. Phinney DG, Prockop DJ (2007) Concise review: mesenchymal stem/multipotent stromal cells: the state of transdifferentiation and modes of tissue repair-current views. Stem Cells 25(11):2896-2902

27. Kolf CM, Cho E, Tuan RS (2007) Mesenchymal stromal cells. Biology of adult mesenchymal stem cells: regulation of niche, self-renewal and differentiation. Arthritis Res Ther 9(1):204

28. Mitchell KE, Weiss ML, Mitchell BM et al (2003) Matrix cells from Wharton's jelly form neurons and glia. Stem Cells 21(1):50-60

29. Alaminos M, Perez-Kohler B, Garzon I et al (2010) Transdifferentiation potentiality of human Wharton's jelly stem cells towards vascular endothelial cells. J Cell Physiol 223(3):640-647

30. Liqing Y, Jia G, Jiqing C et al (2011) Directed differentiation of motor neuron cell-like cells from human adipose-derived stem cells in vitro. NeuroReport 22(8):370-373

31. Baer PC, Geiger H (2012) Adipose-derived mesenchymal stro$\mathrm{mal} / \mathrm{stem}$ cells: tissue localization, characterization, and heterogeneity. Stem Cells Int 2012:812693

32. Maltman DJ, Hardy SA, Przyborski SA (2011) Role of mesenchymal stem cells in neurogenesis and nervous system repair. Neurochem Int 59(3):347-356
33. Meyerrose T, Olson S, Pontow S et al (2010) Mesenchymal stem cells for the sustained in vivo delivery of bioactive factors. Adv Drug Deliv Rev 62(12):1167-1174

34. Skalnikova H, Motlik J, Gadher SJ et al (2011) Mapping of the secretome of primary isolates of mammalian cells, stem cells and derived cell lines. Proteomics 11(4):691-708

35. Chen L, Tredget EE, Wu PY et al (2008) Paracrine factors of mesenchymal stem cells recruit macrophages and endothelial lineage cells and enhance wound healing. PLoS One 3(4):e1886

36. Block GJ, Ohkouchi S, Fung F et al (2009) Multipotent stromal cells are activated to reduce apoptosis in part by upregulation and secretion of stanniocalcin-1. Stem Cells 27(3):670-681

37. Wagner J, Kean T, Young R et al (2009) Optimizing mesenchymal stem cell-based therapeutics. Curr Opin Biotechnol 20(5):531-536

38. Baglio SR, Pegtel DM, Baldini N (2012) Mesenchymal stem cell secreted vesicles provide novel opportunities in (stem) cell-free therapy. Front Physiol 3:359

39. Valadi H, Ekstrom K, Bossios A et al (2007) Exosome-mediated transfer of mRNAs and microRNAs is a novel mechanism of genetic exchange between cells. Nat Cell Biol 9(6):654-659

40. Pegtel DM, Cosmopoulos K, Thorley-Lawson DA et al (2010) Functional delivery of viral miRNAs via exosomes. Proc Natl Acad Sci USA 107(14):6328-6333

41. Lai RC, Arslan F, Lee MM et al (2010) Exosome secreted by MSC reduces myocardial ischemia/reperfusion injury. Stem Cell Res 4(3):214-222

42. Chen TS, Arslan F, Yin Y et al (2011) Enabling a robust scalable manufacturing process for therapeutic exosomes through oncogenic immortalization of human ESC-derived MSCs. J Trans1 Med 9:47

43. Shi Y, Hu G, Su J et al (2010) Mesenchymal stem cells: a new strategy for immunosuppression and tissue repair. Cell Res 20(5):510-518

44. Kode JA, Mukherjee S, Joglekar MV et al (2009) Mesenchymal stem cells: immunobiology and role in immunomodulation and tissue regeneration. Cytotherapy 11(4):377-391

45. Puissant B, Barreau C, Bourin P et al (2005) Immunomodulatory effect of human adipose tissue-derived adult stem cells: comparison with bone marrow mesenchymal stem cells. Br J Haematol 129(1):118-129

46. Lanza C, Morando S, Voci A et al (2009) Neuroprotective mesenchymal stem cells are endowed with a potent antioxidant effect in vivo. J Neurochem 110(5):1674-1684

47. Caplan AI, Dennis JE (2006) Mesenchymal stem cells as trophic mediators. J Cell Biochem 98(5):1076-1084

48. Crigler L, Robey RC, Asawachaicharn A et al (2006) Human mesenchymal stem cell subpopulations express a variety of neuro-regulatory molecules and promote neuronal cell survival and neuritogenesis. Exp Neurol 198(1):54-64

49. Nakano N, Nakai Y, Seo TB et al (2010) Characterization of conditioned medium of cultured bone marrow stromal cells. Neurosci Lett 483(1):57-61

50. Wilkins A, Kemp K, Ginty M et al (2009) Human bone marrowderived mesenchymal stem cells secrete brain-derived neurotrophic factor which promotes neuronal survival in vitro. Stem Cell Res 3(1):63-70

51. Ribeiro CA, Salgado AJ, Fraga JS et al (2011) The secretome of bone marrow mesenchymal stem cells-conditioned media varies with time and drives a distinct effect on mature neurons and glial cells (primary cultures). J Tissue Eng Regen Med 5(8):668-672

52. Cova L, Armentero MT, Zennaro E et al (2010) Multiple neurogenic and neurorescue effects of human mesenchymal stem cell after transplantation in an experimental model of Parkinson's disease. Brain Res 1311:12-27

\begin{tabular}{lll|} 
Journal : Large 18 & Dispatch : 15-2-2013 & Pages : 12 \\
Article No : $\mathbf{1 2 9 0}$ & $\square$ LE & $\square$ TYPESET \\
MS Code : $\mathbf{1 2 9 0}$ & $\square \quad \mathrm{CP}$ & $\square$ DISK \\
\hline
\end{tabular}


53. Nicaise C, Mitrecic D, Pochet R (2011) Brain and spinal cord affected by amyotrophic lateral sclerosis induce differential growth factors expression in rat mesenchymal and neural stem cells. Neuropathol Appl Neurobiol 37(2):179-188

54. Rehman J, Traktuev D, Li J et al (2004) Secretion of angiogenic and antiapoptotic factors by human adipose stromal cells. Circulation 109(10):1292-1298

55. Salgado AJ, Reis RL, Sousa NJ et al (2010) Adipose tissue derived stem cells secretome: soluble factors and their roles in regenerative medicine. Curr Stem Cell Res Ther 5(2): $103-110$

56. Lu S, Lu C, Han Q et al (2011) Adipose-derived mesenchymal stem cells protect PC12 cells from glutamate excitotoxicityinduced apoptosis by upregulation of XIAP through PI3-K/Akt activation. Toxicology 279(1-3):189-195

57. Tan B, Luan Z, Wei X et al (2011) AMP-activated kinase mediates adipose stem cell-stimulated neuritogenesis of PC12 cells. Neuroscience 181:40-47

58. Wei X, Du Z, Zhao L et al (2009) IFATS collection: the conditioned media of adipose stromal cells protect against hypoxiaischemia-induced brain damage in neonatal rats. Stem Cells 27(2):478-488

59. Ribeiro CA, Fraga JS, Graos M et al (2012) The secretome of stem cells isolated from the adipose tissue and Wharton jelly acts differently on central nervous system derived cell populations. Stem Cell Res Ther 3(3):18

60. Arboleda D, Forostyak S, Jendelova P et al (2011) Transplantation of predifferentiated adipose-derived stromal cells for the treatment of spinal cord injury. Cell Mol Neurobiol 31(7):1113-1122

61. Egashira Y, Sugitani S, Suzuki Y et al (2012) The conditioned medium of murine and human adipose-derived stem cells exerts neuroprotective effects against experimental stroke model. Brain Res 1461:87-95

62. Lopatina T, Kalinina N, Karagyaur M et al (2011) Adiposederived stem cells stimulate regeneration of peripheral nerves: BDNF secreted by these cells promotes nerve healing and axon growth de novo. PLoS One 6(3):e17899

63. Koh SH, Kim KS, Choi MR et al (2008) Implantation of human umbilical cord-derived mesenchymal stem cells as a neuroprotective therapy for ischemic stroke in rats. Brain Res 1229:233-248

64. Salgado AJ, Fraga JS, Mesquita AR et al (2010) Role of human umbilical cord mesenchymal progenitors conditioned media in neuronal/glial cell densities, viability, and proliferation. Stem Cells Dev 19(7):1067-1074

65. Ding DC, Shyu WC, Chiang MF et al (2007) Enhancement of neuroplasticity through upregulation of beta1-integrin in human umbilical cord-derived stromal cell implanted stroke model. Neurobiol Dis 27(3):339-353

66. Abe K, Yamashita T, Takizawa S et al (2012) Stem cell therapy for cerebral ischemia: from basic science to clinical applications. J Cereb Blood Flow Metab 32(7):1317-1331

67. Pal R, Gopinath C, Rao NM et al (2010) Functional recovery after transplantation of bone marrow-derived human mesenchymal stromal cells in a rat model of spinal cord injury. Cytotherapy 12(6):792-806

68. Kim HJ, Kim HJ, Lee JY et al (2011) Phenotype analysis in patients with early onset Parkinson's disease with and without parkin mutations. J Neurol 258(12):2260-2267

69. Chung YC, Ko HW, Bok E et al (2010) The role of neuroinflammation on the pathogenesis of Parkinson's disease. BMB Rep 43(4):225-232

70. Anisimov SV (2009) Cell-based therapeutic approaches for Parkinson's disease: progress and perspectives. Rev Neurosci 20(5-6):347-381
71. Singh N, Pillay V, Choonara YE (2007) Advances in the treatment of Parkinson's disease. Prog Neurobiol 81(1):29-44

72. Muller T, Hefter H, Hueber R et al (2004) Is levodopa toxic? J Neurol 251(Suppl 6):VI/44-VI/46

73. Muller T, Renger K, Kuhn W (2004) Levodopa-associated increase of homocysteine levels and sural axonal neurodegeneration. Arch Neurol 61(5):657-660

74. Weiner WJ (2006) Advances in the diagnosis, treatment, and understanding of Parkinson's disease and parkinsonism. Rev Neurol Dis 3(4):191-194

75. Lindvall O, Brundin P, Widner $\mathrm{H}$ et al (1990) Grafts of fetal dopamine neurons survive and improve motor function in Parkinson's disease. Science 247(4942):574-577

76. Lindvall O, Rehncrona S, Brundin P et al (1989) Human fetal dopamine neurons grafted into the striatum in two patients with severe Parkinson's disease. A detailed account of methodology and a 6-month follow-up. Arch Neurol 46(6):615-631

77. Lindvall O, Widner H, Rehncrona S et al (1992) Transplantation of fetal dopamine neurons in Parkinson's disease: one-year clinical and neurophysiological observations in two patients with putaminal implants. Ann Neurol 31(2):155-165

78. Sawle GV, Bloomfield PM, Bjorklund A et al (1992) Transplantation of fetal dopamine neurons in Parkinson's disease: PET [18F]6-L-fluorodopa studies in two patients with putaminal implants. Ann Neurol 31(2):166-173

79. Azari MF, Mathias L, Ozturk E et al (2010) Mesenchymal stem cells for treatment of CNS injury. Curr Neuropharmacol 8(4):316-323

80. Wang Y, Chen S, Yang D et al (2007) Stem cell transplantation: a promising therapy for Parkinson's disease. J Neuroimmune Pharmacol 2(3):243-250

81. Bouchez G, Sensebe L, Vourc'h P et al (2008) Partial recovery of dopaminergic pathway after graft of adult mesenchymal stem cells in a rat model of Parkinson's disease. Neurochem Int 52(7):1332-1342

82. Levy YS, Bahat-Stroomza M, Barzilay R et al (2008) Regenerative effect of neural-induced human mesenchymal stromal cells in rat models of Parkinson's disease. Cytotherapy 10(4): 340-352

83. Jin GZ, Cho SJ, Lee YS et al (2010) Intrastriatal grafts of mesenchymal stem cells in adult intact rats can elevate tyrosine hydroxylase expression and dopamine levels. Cell Biol Int 34(1):135-140

84. McCoy MK, Martinez TN, Ruhn KA et al (2008) Autologous transplants of Adipose-Derived Adult Stromal (ADAS) cells afford dopaminergic neuroprotection in a model of Parkinson's disease. Exp Neurol 210(1):14-29

85. Fu YS, Cheng YC, Lin MY et al (2006) Conversion of human umbilical cord mesenchymal stem cells in Wharton's jelly to dopaminergic neurons in vitro: potential therapeutic application for Parkinsonism. Stem Cells 24(1):115-124

86. Kan I, Ben-Zur T, Barhum Y et al (2007) Dopaminergic differentiation of human mesenchymal stem cells-utilization of bioassay for tyrosine hydroxylase expression. Neurosci Lett 419(1):28-33

87. Chao YX, He BP, Tay SS (2009) Mesenchymal stem cell transplantation attenuates blood brain barrier damage and neuroinflammation and protects dopaminergic neurons against MPTP toxicity in the substantia nigra in a model of Parkinson's disease. J Neuroimmunol 216(1-2):39-50

88. Thomas MG, Stone L, Evill L et al (2011) Bone marrow stromal cells as replacement cells for Parkinson's disease: generation of an anatomical but not functional neuronal phenotype. Transl Res 157(2):56-63

89. Wang F, Yasuhara T, Shingo T et al (2010) Intravenous administration of mesenchymal stem cells exerts therapeutic effects on

\begin{tabular}{llll|} 
Journal : Large 18 & Dispatch : 15-2-2013 & Pages : 12 \\
Article No : $\mathbf{1 2 9 0}$ & $\square$ LE & $\square$ TYPESET \\
MS Code : $\mathbf{1 2 9 0}$ & $\square \mathrm{CP}$ & $\square$ DISK \\
\hline
\end{tabular}


parkinsonian model of rats: focusing on neuroprotective effects of stromal cell-derived factor-1alpha. BMC Neurosci 11:52

90. Weiss ML, Medicetty S, Bledsoe AR et al (2006) Human umbilical cord matrix stem cells: preliminary characterization and effect of transplantation in a rodent model of Parkinson's disease. Stem Cells 24(3):781-792

91. Sadan O, Bahat-Stromza M, Barhum Y et al (2009) Protective effects of neurotrophic factor-secreting cells in a 6-OHDA rat model of Parkinson disease. Stem Cells Dev 18(8):1179-1190

92. Sadan O, Shemesh N, Cohen Y et al (2009) Adult neurotrophic factor-secreting stem cells: a potential novel therapy for neurodegenerative diseases. Isr Med Assoc J 11(4):201-204

93. Blandini F, Cova L, Armentero MT et al (2010) Transplantation of undifferentiated human mesenchymal stem cells protects against 6-hydroxydopamine neurotoxicity in the rat. Cell Transplant 19(2):203-217

94. Olanow CW (2008) Levodopa/dopamine replacement strategies in Parkinson's disease-future directions. Mov Disord 23(Suppl 3):S613-S622

95. Moloney TC, Rooney GE, Barry FP et al (2010) Potential of rat bone marrow-derived mesenchymal stem cells as vehicles for delivery of neurotrophins to the Parkinsonian rat brain. Brain Res 1359:33-43

96. Mortazavi MM, Verma K, Tubbs RS et al (2011) Cellular and paracellular transplants for spinal cord injury: a review of the literature. Childs Nerv Syst 27(2):237-243

97. Watson RA, Yeung TM (2011) What is the potential of oligodendrocyte progenitor cells to successfully treat human spinal cord injury? BMC Neurol 11:113

98. Rabchevsky AG, Patel SP, Springer JE (2011) Pharmacological interventions for spinal cord injury: where do we stand? How might we step forward? Pharmacol Ther 132(1):15-29

99. Shang AJ, Hong SQ, Xu Q et al (2011) NT-3-secreting human umbilical cord mesenchymal stromal cell transplantation for the treatment of acute spinal cord injury in rats. Brain Res 1391:102-113

100. Zurita M, Vaquero J (2006) Bone marrow stromal cells can achieve cure of chronic paraplegic rats: functional and morphological outcome one year after transplantation. Neurosci Lett 402(1-2):51-56

101. Ide C, Nakai Y, Nakano $\mathrm{N}$ et al (2010) Bone marrow stromal cell transplantation for treatment of sub-acute spinal cord injury in the rat. Brain Res 1332:32-47

102. Yang CC, Shih YH, Ko MH et al (2008) Transplantation of human umbilical mesenchymal stem cells from Wharton's jelly after complete transection of the rat spinal cord. PLoS One 3(10):e3336

103. Vaquero J, Zurita M (2009) Bone marrow stromal cells for spinal cord repair: a challenge for contemporary neurobiology. Histol Histopathol 24(1):107-116

104. Wright KT, El Masri W, Osman A et al (2011) Concise review: bone marrow for the treatment of spinal cord injury: mechanisms and clinical applications. Stem Cells 29(2):169-178

105. Wright KT, El Masri W, Osman A et al (2007) Bone marrow stromal cells stimulate neurite outgrowth over neural proteoglycans (CSPG), myelin associated glycoprotein and Nogo-A. Biochem Biophys Res Commun 354(2):559-566

106. Lu P, Jones LL, Tuszynski MH (2005) BDNF-expressing marrow stromal cells support extensive axonal growth at sites of spinal cord injury. Exp Neurol 191(2):344-360

107. Neuhuber B, Timothy Hilmes B, Shumsky JS et al (2005) Axon growth and recovery of function supported by human bone marrow stromal cells in the injured spinal cord exhibit donor variations. Brain Res 1035(1):73-85

108. Gu W, Zhang F, Xue Q et al (2010) Transplantation of bone marrow mesenchymal stem cells reduces lesion volume and induces axonal regrowth of injured spinal cord. Neuropathology 30(3):205-217

109. Park HW, Lim MJ, Jung H et al (2010) Human mesenchymal stem cell-derived Schwann cell-like cells exhibit neurotrophic effects, via distinct growth factor production, in a model of spinal cord injury. Glia 58(9):1118-1132

110. Zhang L, Zhang HT, Hong SQ et al (2009) Cografted Wharton's jelly cells-derived neurospheres and BDNF promote functional recovery after rat spinal cord transection. Neurochem Res 34(11):2030-2039

111. Kim KN, Oh SH, Lee KH et al (2006) Effect of human mesenchymal stem cell transplantation combined with growth factor infusion in the repair of injured spinal cord. Acta Neurochir Suppl 99:133-136

112. Karamouzian S, Nematollahi-Mahani SN, Nakhaee $\mathrm{N}$ et al (2012) Clinical safety and primary efficacy of bone marrow mesenchymal cell transplantation in subacute spinal cord injured patients. Clin Neurol Neurosurg 114(7):935-939

113. Saito F, Nakatani T, Iwase M et al (2008) Spinal cord injury treatment with intrathecal autologous bone marrow stromal cell transplantation: the first clinical trial case report. J Trauma 64(1):53-59

114. Saito F, Nakatani T, Iwase M et al (2012) Administration of cultured autologous bone marrow stromal cells into cerebrospinal fluid in spinal injury patients: a pilot study. Restor Neurol Neurosci 30(2):127-136

115. Hawryluk GW, Mothe A, Wang J et al (2012) An in vivo characterization of trophic factor production following neural precursor cell or bone marrow stromal cell transplantation for spinal cord injury. Stem Cells Dev 21(12):2222-2238

116. Fehlings MG, Vawda R (2011) Cellular treatments for spinal cord injury: the time is right for clinical trials. Neurotherapeutics 8(4):704-720

117. Yazdani SO, Pedram M, Hafizi M et al (2012) A comparison between neurally induced bone marrow derived mesenchymal stem cells and olfactory ensheathing glial cells to repair spinal cord injuries in rat. Tissue Cell 44(4):205-213

118. Lindvall O, Bjorklund A (2004) Cell replacement therapy: helping the brain to repair itself. NeuroRx 1(4):379-381

119. Ahmad M. Graham SH (2010) Inflammation after stroke: mechanisms and therapeutic approaches. Transl Stroke Res 1(2):74-84

120. Shafi N, Kasner SE (2011) Treatment of acute ischemic stroke: beyond thrombolysis and supportive care. Neurotherapeutics $8(3): 425-433$

121. Locatelli F, Bersano A, Ballaio E et al (2009) Stem cell therapy in stroke. Cell Mol Life Sci 66(5):757-772

122. Komatsu K, Honmou O, Suzuki J et al (2010) Therapeutic time window of mesenchymal stem cells derived from bone marrow after cerebral ischemia. Brain Res 1334:84-92

123. Keimpema E, Fokkens MR, Nagy Z et al (2009) Early transient presence of implanted bone marrow stem cells reduces lesion size after cerebral ischaemia in adult rats. Neuropathol Appl Neurobiol 35(1):89-102

124. Zheng W, Honmou O, Miyata K et al (2010) Therapeutic benefits of human mesenchymal stem cells derived from bone marrow after global cerebral ischemia. Brain Res 1310:8-16

125. Kurozumi K, Nakamura K, Tamiya T et al (2005) Mesenchymal stem cells that produce neurotrophic factors reduce ischemic damage in the rat middle cerebral artery occlusion model. Mol Ther 11(1):96-104

126. Wang Y, Deng Y, Zhou GQ (2008) SDF-1alpha/CXCR4-mediated migration of systemically transplanted bone marrow stromal cells towards ischemic brain lesion in a rat model. Brain Res 1195:104-112

127. Wakabayashi K, Nagai A, Sheikh AM et al (2010) Transplantation of human mesenchymal stem cells promotes functional

\begin{tabular}{lll|} 
Journal : Large 18 & Dispatch : 15-2-2013 & Pages : 12 \\
Article No : $\mathbf{1 2 9 0}$ & $\square$ LE & $\square$ TYPESET \\
MS Code : $\mathbf{1 2 9 0}$ & $\square \quad \mathrm{CP}$ & $\square$ DISK \\
\hline
\end{tabular}


improvement and increased expression of neurotrophic factors in a rat focal cerebral ischemia model. J Neurosci Res 88(5): 1017-1025

128. Leu S, Lin YC, Yuen CM et al (2010) Adipose-derived mesenchymal stem cells markedly attenuate brain infarct size and improve neurological function in rats. J Transl Med 8:63

129. Tang YL, Zhao Q, Qin X et al (2005) Paracrine action enhances the effects of autologous mesenchymal stem cell transplantation on vascular regeneration in rat model of myocardial infarction. Ann Thorac Surg 80(1):229-236 discussion 236-7

130. Banas A, Teratani T, Yamamoto Y et al (2008) IFATS collection: in vivo therapeutic potential of human adipose tissue mesenchymal stem cells after transplantation into mice with liver injury. Stem Cells 26(10):2705-2712

131. Chen JR, Cheng GY, Sheu CC et al (2008) Transplanted bone marrow stromal cells migrate, differentiate and improve motor function in rats with experimentally induced cerebral stroke. J Anat 213(3):249-258

132. Bang OY, Lee JS, Lee PH et al (2005) Autologous mesenchymal stem cell transplantation in stroke patients. Ann Neurol 57(6):874-882

133. Lee JS, Hong JM, Moon GJ et al (2010) A long-term followup study of intravenous autologous mesenchymal stem cell transplantation in patients with ischemic stroke. Stem Cells 28(6):1099-1106

134. Roh JK, Jung KH, Chu K (2008) Adult stem cell transplantation in stroke: its limitations and prospects. Curr Stem Cell Res Ther 3(3): 185-196

135. Lanfranconi S, Locatelli F, Corti S et al (2011) Growth factors in ischemic stroke. J Cell Mol Med 15(8):1645-1687

136. Bonfield TL, Nolan Koloze MT, Lennon DP et al (2010) Defining human mesenchymal stem cell efficacy in vivo. J Inflamm (Lond) 7:51

137. Joyce N, Annett G, Wirthlin L et al (2010) Mesenchymal stem cells for the treatment of neurodegenerative disease. Regen Med 5(6):933-946
138. Momin EN, Mohyeldin A, Zaidi HA et al (2010) Mesenchymal stem cells: new approaches for the treatment of neurological diseases. Curr Stem Cell Res Ther 5(4):326-344

139. Lee PH, Park HJ (2009) Bone marrow-derived mesenchymal stem cell therapy as a candidate disease-modifying strategy in Parkinson's disease and multiple system atrophy. J Clin Neurol 5(1):1-10

140. Roobrouck VD, Clavel C, Jacobs SA et al (2011) Differentiation potential of human postnatal mesenchymal stem cells, mesoangioblasts, and multipotent adult progenitor cells reflected in their transcriptome and partially influenced by the culture conditions. Stem Cells 29(5):871-882

141. Ranganath SH, Levy O, Inamdar MS et al (2012) Harnessing the mesenchymal stem cell secretome for the treatment of cardiovascular disease. Cell Stem Cell 10(3):244-258

142. Dharmasaroja P (2009) Bone marrow-derived mesenchymal stem cells for the treatment of ischemic stroke. J Clin Neurosci 16(1):12-20

143. Liu Z, Li Z, Zhang X et al (2008) Contralesional axonal remodeling of the corticospinal system in adult rats after stroke and bone marrow stromal cell treatment. Stroke 39(9):2571-2577

144. Choi YJ, Li WY, Moon GJ et al (2010) Enhancing trophic support of mesenchymal stem cells by ex vivo treatment with trophic factors. J Neurol Sci 298(1-2):28-34

145. Li WY, Choi WJ, Lee PH et al (2008) Mesenchymal stem cells for ischemic stroke: changes in effects after ex vivo culturing. Cell Transplant 17(9):1045-1059

146. Rivera FJ, Siebzehnrubi FA, Kandasamy M et al (2009) Mesenchymal stem cells promote oligodendroglial differentiation in hippocampal slice cultures. Cell Physiol Biochem 24(3-4):317-324

147. English K, French A, Wood KJ (2010) Mesenchymal stromal cells: facilitators of successful transplantation? Cell Stem Cell 7(4):431-442

\begin{tabular}{lll|} 
Journal : Large 18 & Dispatch : 15-2-2013 & Pages : 12 \\
Article No : 1290 & $\square$ LE & $\square$ TYPESET \\
MS Code : $\mathbf{1 2 9 0}$ & $\square \quad C P$ & $\square$ DISK \\
\hline
\end{tabular}

